\title{
Computational fluid dynamics simulation of thermal comfort in naturally ventilated room
}

\author{
Andrzej Raczkowski ${ }^{1, *}$, Zbigniew Suchorab ${ }^{1}$, and Przemysław Brzyski ${ }^{2}$ \\ ${ }^{1}$ Lublin University of Technology, Faculty of Environmental Engineering, Nadbystrzycka 40B, 20-618 Lublin, Poland \\ ${ }^{2}$ Lublin University of Technology, Faculty of Faculty of Civil Engineering and Architecture, Nadbystrzycka 40, 20-618 Lublin, \\ Poland
}

\begin{abstract}
The paper presents experimental measurements and numerical simulation of thermal environment in naturally ventilated room by a fresh air valve. For the aim of Computer Fluid Dynamics (CFD) simulations, a model room was created. The fresh air valve is located in an occupied space, at the external wall. It has a major effect on mixing indoor and outdoor air, temperature profiles, thermal condition and indoor air quality of the rooms during the heating period. To determine the thermal condition of a naturally ventilated building, PN-EN 15251:2012 standard was used. According to the standard, using PMV/PPD is suitable for evaluating the thermal environment. In the naturally ventilated buildings, the following criteria are very important for local thermal discomfort: draught, radiant temperature asymmetry and vertical air temperature differences. To compare the simulation results, real air temperatures were measured by the thermocouples in a day room having the same geometry. A series of simulations has been carried out to determine the profiles of temperature and velocity of indoor air. Obtained results prove correlation with calculations of profiles of indoor air temperature, estimated using the thermocouples.
\end{abstract}

\section{Introduction}

People spend about $90 \%$ of their lives indoors. Thus, it is important to ensure safe, healthy and comfortable conditions in buildings. Most of the multi-family residential buildings in Poland have a natural ventilation system.

Ventilation systems have a direct impact on the occupants' comfort through temperatures and air movement and indoor air quality. In Poland, naturally ventilated rooms have poor indoor climate during heating seasons [1]. This is due to the reduced air exchange by the occupants to save energy. Reduction in an air exchange rate in the room leads to an appearance of the SBS (Sick Build Syndrome). Wrong overall design of natural ventilation system may be a reason for poor air quality too. It may be caused by using too small fresh air valves or installing them in wrong places. Improper placement of cold outdoor air valves causes incorrect mixing of indoor and outdoor air and formation of cold flows in the occupied area. This may cause local thermal discomfort.

Indoor air quality regulations make it not possible to achieve reasonable decrease in heat demand by the reduction of volume of a fresh air inlet[2].

There are many computational tools to analyse fluid flows. Commercial CFD program Ansys Fluent and Autodesk CFD are often used. They allow to study water [3] and air flow [4-6]. In this paper Autodesk CFD was used. Through this tool temperatures, velocities, pressure and another fluid characteristic can be calculated.

CFD is commonly used to study airflow in rooms. The method has been used for many years as a research tool [7]. Now it is routinely used in research and teaching at area of indoor. It provides full control over the boundary conditions and data for each point of the modelled environment, together with the complex geometry in full scale. CFD modelling is also able to allow the efficient parametric analysis of different configuration and for various conditions [8]. But it always is imperative to ensure accuracy and reliability of CFD modelling and thus perform the verification and validation with experimental methods [7].

The objective of this study is to present the CFD simulation of natural ventilation performance in the room during the heating period. Analyses of thermal comfort are based on Predicted Mean Vote (PMV) and Predicted Percentage of Dissatisfied (PPD) models [910].

\section{Experimental measurements}

A naturally ventilated room being a part of the dwelling, built in 1997 in Lublin, Poland, was chosen in order to study indoor environmental conditions. Dimensions of the room are $4.15 \mathrm{~m} \times 2.60 \mathrm{~m} \times 2.50 \mathrm{~m}$. One external wall length equals $2.60 \mathrm{~m}$ facing south direction. One plasticsteel window is located $0.9 \mathrm{~m}$ from the floor level. The window height is $1.5 \mathrm{~m}$ and width $1.2 \mathrm{~m}$. During the

*Corresponding author: a.raczkowski@pollub.pl 
experiment, the air entered the room through the fresh air valve, situated on the external wall and located $0.5 \mathrm{~m}$ above floor level. Two vertical exhaust ducts are placed in the kitchen and the bathroom. Central heating system is used in the building during the winter period.

To measure temperatures of air in the room the thermocouples were used. They were installed $0.1 \mathrm{~m}$, $0.6 \mathrm{~m}, 1.1 \mathrm{~m}, 1.7 \mathrm{~m}$ above floor level, situated in the occupied area of the room near sitting people (M1-M5) (Fig.1). The air flow was measured at the fresh air valve by wing anemometer (TESTO) $\left(\mathrm{V}_{1}\right)$ (Fig.1). Outdoor air temperature (M0) was equal $-9.9 \pm 0.1^{\circ} \mathrm{C}$ and relative air humidity $95 \pm 2 \%$ (M0) (Fig.1).

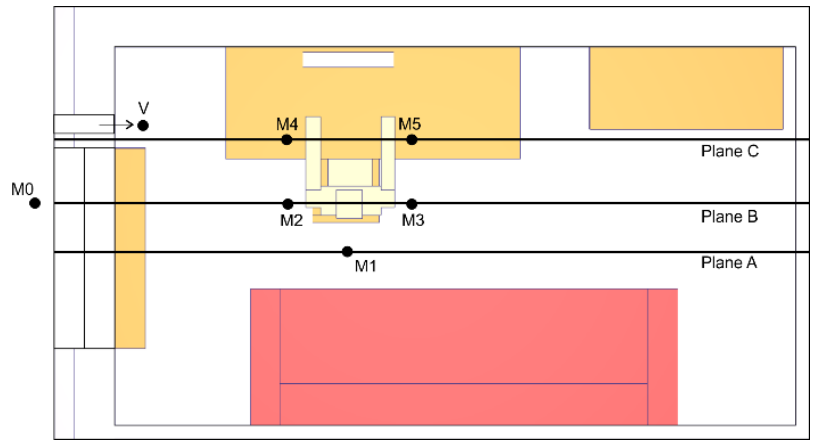

Fig. 1. Measuring setup.

\section{CFD analysis}

The naturally ventilated room has been replicated in detail as a computational model, based on construction drawings, for CFD simulations. The model was constructed according to real dimensions of the room presented in the previous sub-section. The geometry model was built using AutoCAD software tool [11].

The airflow and the air temperature were simulated in a naturally ventilated room occupied by one person working on a laptop. Geometrical elements of the modelled room, i.e. the occupant, window, sofa, chair and table, were simplified in this work according to Fig.2. Settings of the CFD model imitated conditions inside the room during field measurements.

The CFD program Autodesk CFD was used for numerical calculations [4][5][12-15].

In this study, $\mathrm{k}-\varepsilon$ two-equation model was used in CFD simulation. It is the most popular one for this type of research. The standard $\mathrm{k}-\varepsilon$ model is a universal turbulence model for prediction of air movement in buildings. The model is based on a transport equation for turbulence kinetic energy $(\mathrm{k})$ and a transport equation for dissipation of turbulent kinetic energy $(\varepsilon)$ [8]. The physical parameters such as air temperature, air pressure and air velocity in the turbulence randomly vary with the time and space. The recommended value of coefficients in the model is given in Table 1 [13-15].

Table 1. Coefficients in k- $\varepsilon$ model.

\begin{tabular}{|c|c|c|c|c|c|}
\hline Coefficients & $\mathrm{c}_{\mu}$ & $\mathrm{c}_{1}$ & $\mathrm{c}_{2}$ & $\sigma_{\mathrm{k}}$ & $\sigma_{\varepsilon}$ \\
\hline Value & 0.09 & 1.44 & 1.92 & 1.0 & 1.3 \\
\hline
\end{tabular}

Boundary conditions for the CFD simulations were set to reproduce the experimental conditions data from in-situ measurements. The inlet element situated on the external wall was assigned with a constant value flow rate of fresh air valve set as $18 \mathrm{~m}^{3} / \mathrm{h}$. Temperature of outdoor air was set as $-10^{\circ} \mathrm{C}$. The boundary on an exhaust element was defined as static pressure outlet air set as $0 \mathrm{~Pa}$. Heat output of the radiator was $400 \mathrm{Watt}$.

The initial condition was the indoor air temperature set as $20^{\circ} \mathrm{C}$.

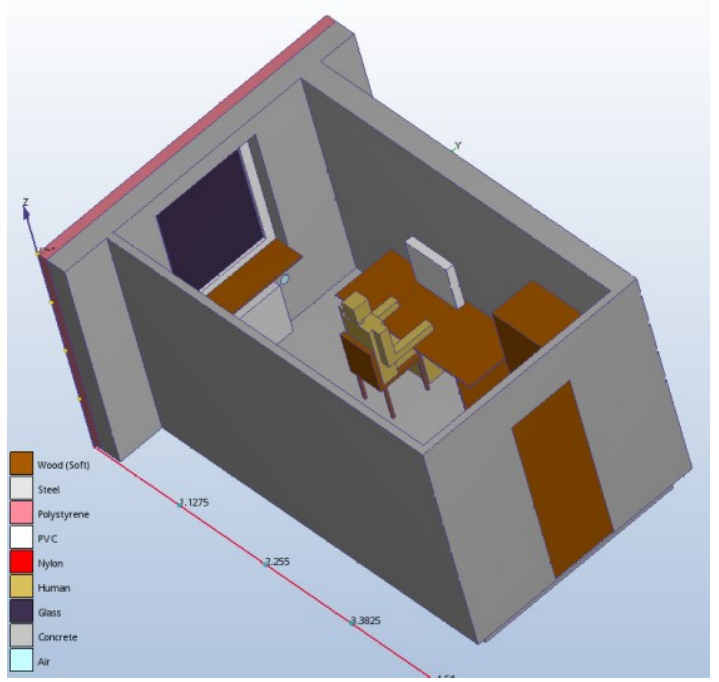

Fig. 2. Geometric model.

\section{Results and discussion}

CFD simulations have been carried out to evaluate the profiles of temperature and velocity of indoor air in naturally ventilated room.

CFD simulation was used to visualise temperature and velocity distribution inside modelled room. Location of two vertical planes: $\mathrm{A}$ in the axis of window, B through the occupant and $\mathrm{C}$ in the axis of legs of sitting human (Fig.1).

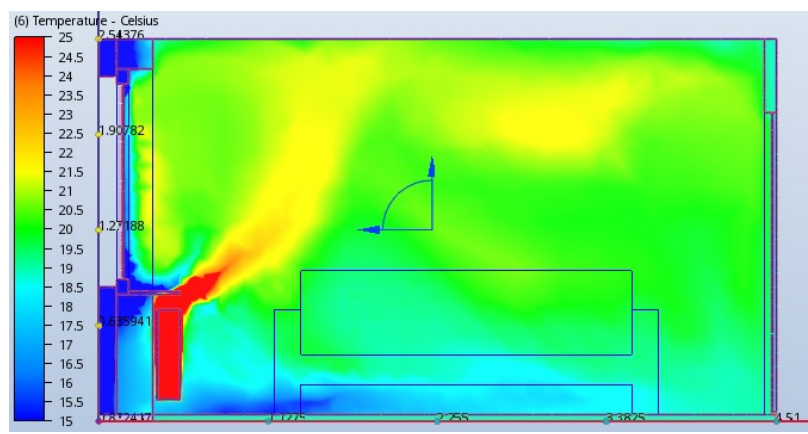

Fig. 3. Temperature distribution at plane A.

The results show the airflow of cold air through the fresh air valve was spread over in lower part of the room. Fig. 3 shows the results of the room air temperature distribution at plane A. Temperature of air varies generally in the ranged from 15 on the window, to $25^{\circ} \mathrm{C}$ at the heat source. Temperatures at the ankles level $(0.1 \mathrm{~m})$ were low and ranged from 16 to $18^{\circ} \mathrm{C}$. Respectively, the average air speeds were $0.09 \mathrm{~m} / \mathrm{s}$ at the ankles level (Fig.4). 


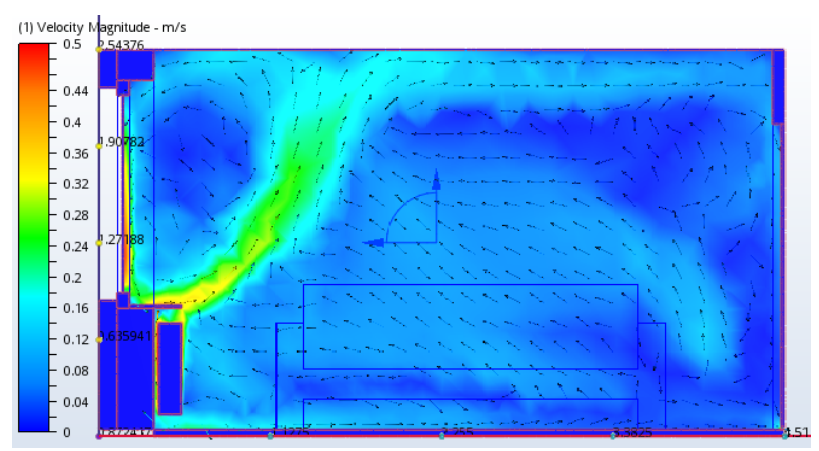

Fig. 4. Air velocity distribution at plane A.

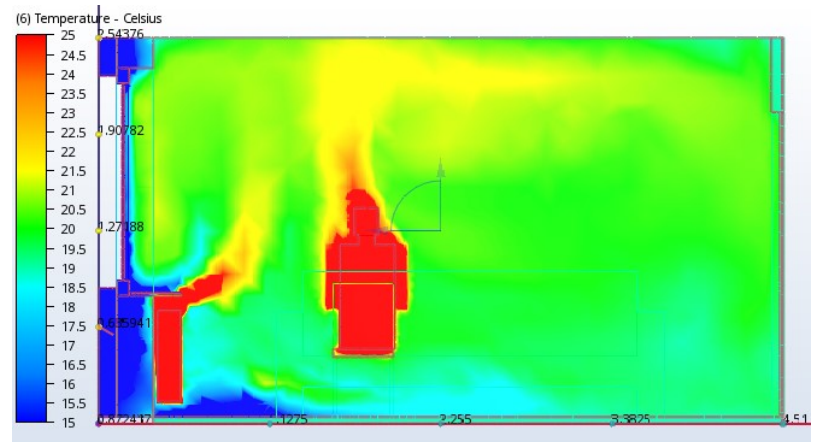

Fig. 5. Temperature distribution at plane B.

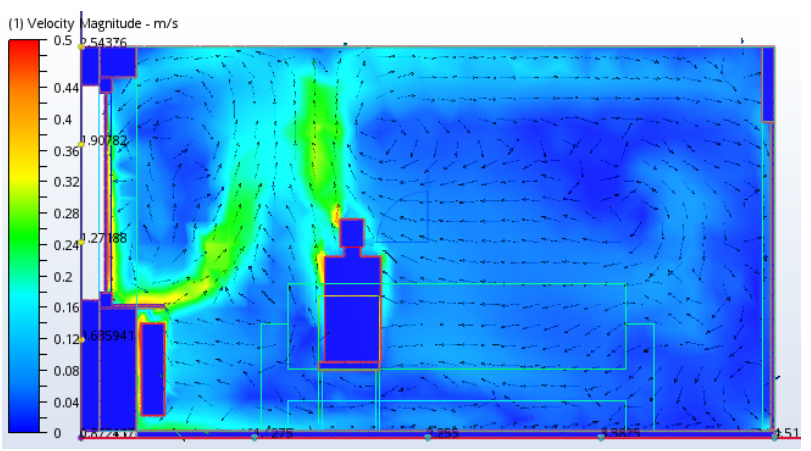

Fig. 6. Air velocity distribution at plane B.

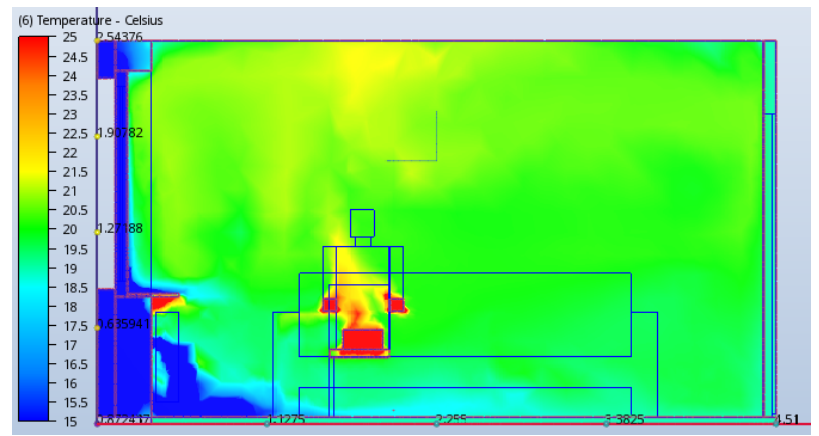

Fig. 7. Temperature distribution at plane C.

Fig. 5 demonstrates the air temperature distribution at plane $\mathrm{B}$. The average air temperature at the ankles level was $19.2^{\circ} \mathrm{C}, 19.5^{\circ} \mathrm{C}$ at the sitting person's waist level $(0.6 \mathrm{~m}), 21.1^{\circ} \mathrm{C}$ at the sitting person's head $(1.1 \mathrm{~m})$ and $21.9^{\circ} \mathrm{C}$ at the standing person's head $(1.7 \mathrm{~m})$.

Respectively, average air speeds were $0.06 \mathrm{~m} / \mathrm{s}$ at the ankles level, $0.08 \mathrm{~m} / \mathrm{s}$ at the sitting person's waist level
$(0.6 \mathrm{~m}), 0.12 \mathrm{~m} / \mathrm{s}$ at the sitting person's head $(1.1 \mathrm{~m})$ and $0.24 \mathrm{~m} / \mathrm{s}$ at the standing person's head (1.7m). (Fig.6).

Fig. 5 shows the prediction of the thermal plume above a simulated person. Maximum velocity of 0.26 $\mathrm{m} / \mathrm{s}$ takes place $24 \mathrm{~cm}$ above the head of the person (Fig.6).

Fig.7 presents the air temperature distribution at plane C. The average air temperature at the ankles level was $19.0^{\circ} \mathrm{C}, 20.3^{\circ} \mathrm{C}$ at the sitting person's waist level $(0.6 \mathrm{~m})$, $20.3^{\circ} \mathrm{C}$ at the sitting person's head $(1.1 \mathrm{~m})$ and $20.4^{\circ} \mathrm{C}$ at the standing person's head. Respectively, the average air speeds were $0.02 \mathrm{~m} / \mathrm{s}$ at the ankles level, $0.08 \mathrm{~m} / \mathrm{s}$ at the sitting person's waist level $(0.6 \mathrm{~m}), 0.08 \mathrm{~m} / \mathrm{s}$ at the sitting person's head $(1.1 \mathrm{~m})$ and $0.04 \mathrm{~m} / \mathrm{s}$ at the standing person's head (1.7m) (Fig.8).

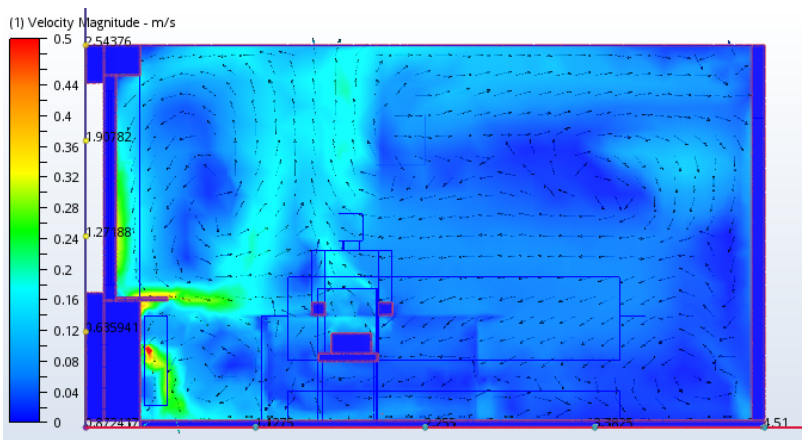

Fig. 8. Air velocity distribution at plane C.

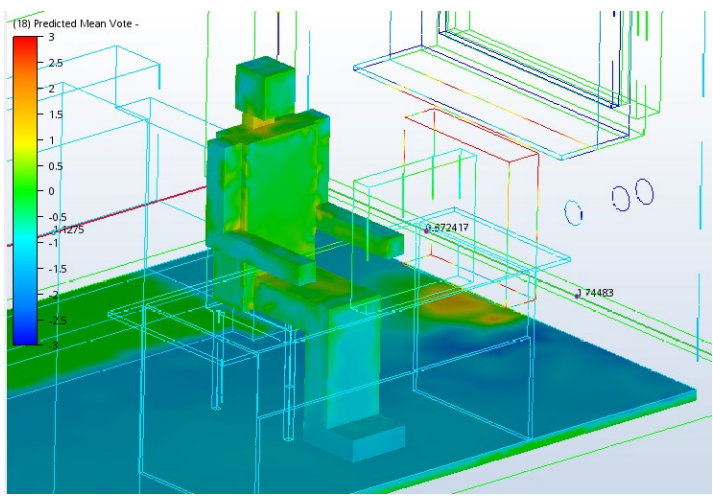

Fig. 9. PMV value distribution at the human model surface.

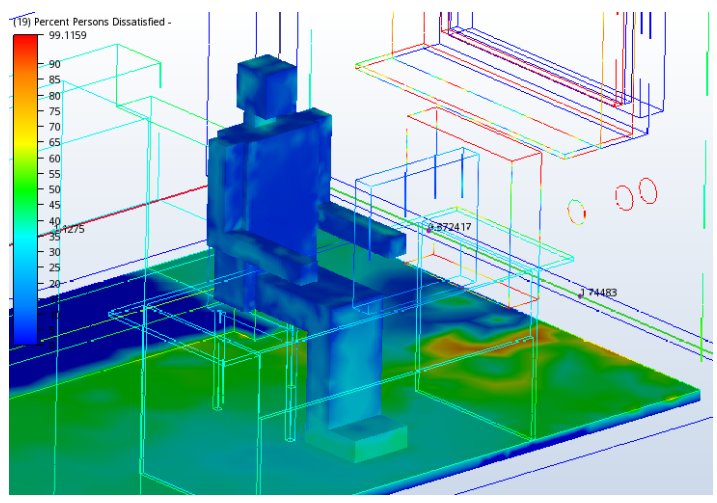

Fig. 10. PPD value distribution at the human model surface. 
Higher air velocities in the room were experienced in area situated near the heat source and above the simulated person, due to convective flows. The cold air entered the room through fresh air valve, and cold layer of air under the floor was created (Fig.5).

In order to determine the thermal condition of a naturally ventilated building, CEN. EN 15251: indoor environment input parameters for design and assessment of energy performance of buildings addressing indoor air quality, thermal environment, lighting and acoustics were used [2].

Fig.9. demonstrates the PMV value on the surface of the human model and on the floor. The PMV value varies generally in the ranged from-1.1 on the legs, -0.4 on the head to 0.5 on the torso. The PMV values indicate that the human occupant might not be comfortable, as his legs were cold.

Effects of cold air from the inlet and hot air from the heat source were shown on the surface of the floor, near external wall, as colourful stains.

PPD is an index that determines prediction of the percentage of people that are dissatisfied with the thermal conditions in the room. Fig. 10 show PPD value on the surface of the human model and on the floor. Highest PPD value is on the legs of the human model and equals about $40 \%, 8 \%$ on the torso and $5 \%$ on the head.

Figs. 11 to 15 demonstrate air temperature profiles inside the room. They show the results of measurements and numerical calculations. As it can be seen from Fig. 11 to 15 , the results of numerical calculations gave slightly higher values than measurements.

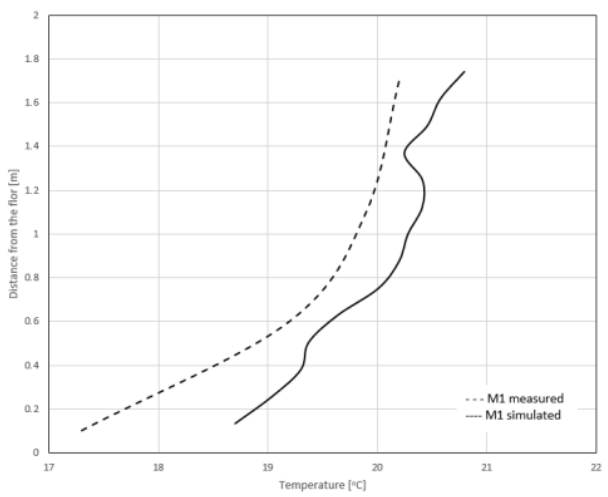

Fig. 11. Measured and simulated air temperatures (pole M1).

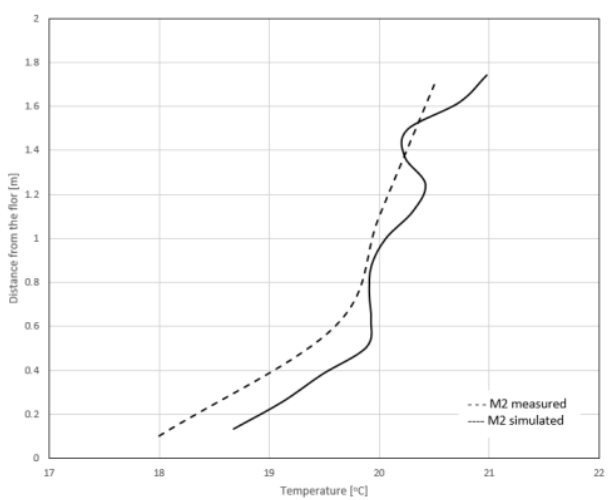

Fig. 12. Measured and simulated air temperatures (pole M2).

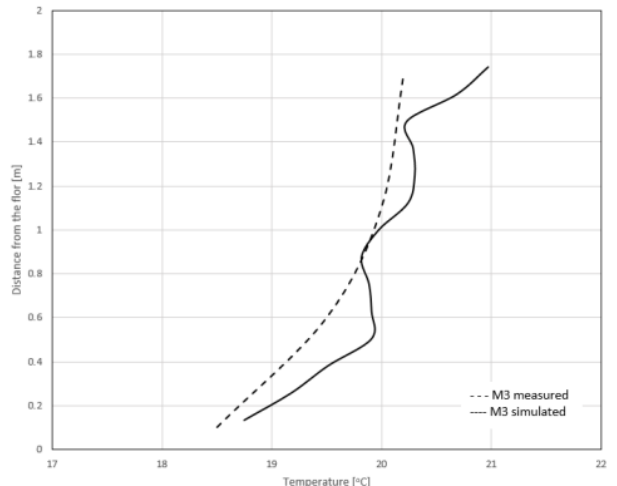

Fig. 13. Measured and simulated air temperatures (pole M3).

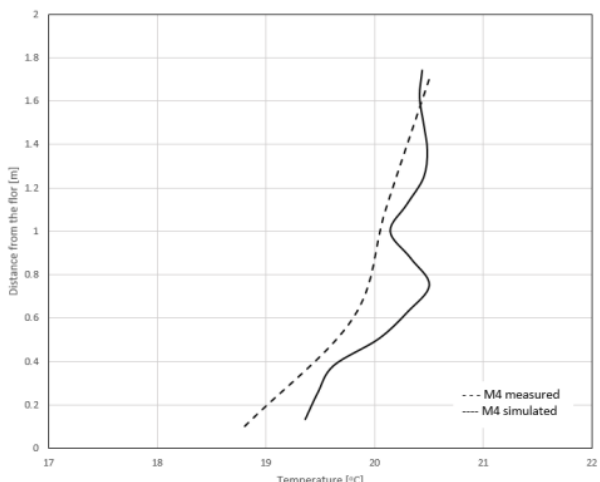

Fig. 14. Measured and simulated air temperatures (pole M4).

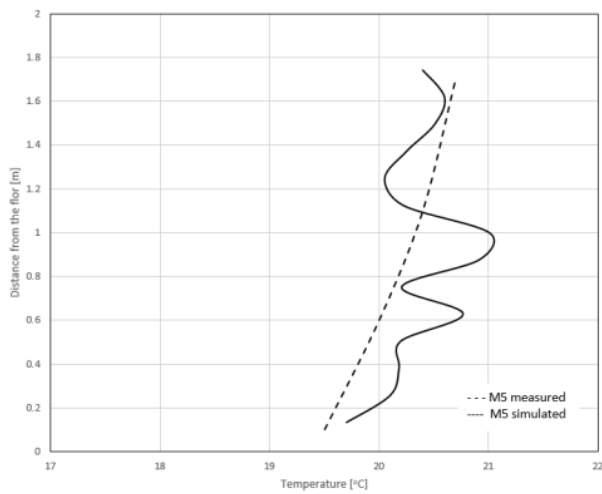

Fig. 15. Measured and simulated air temperatures (pole M5).

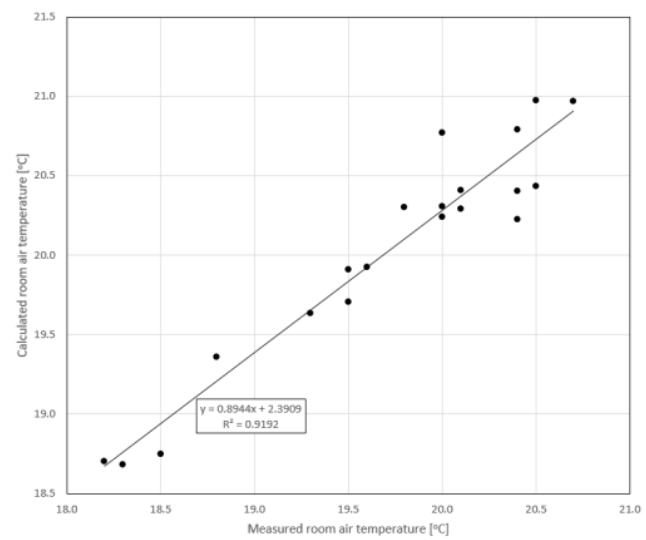

Fig. 16. Dependences between measured indoor air temperature and indoor air temperatures obtained using CFD. 
Correlation between data achieved from measurements and CFD simulation is linear (Fig. 16), with coefficient of determination $\mathrm{R}^{2}$ close to 0.92 . Slope of linear regression between indoor temperatures is different from 1 and equals about 0.89 .

\section{Conclusions}

This paper explains the results of field measurement and verification of CFD model for naturally ventilated room. The CFD model was validated with experimental data and it was used for local thermal comfort prediction within the room. The CFD simulation model was used for the local thermal comfort evaluation, and the PMV and PPD were shown.

According to the conducted calculations of the temperature performance of natural ventilation the following conclusions may be formulated:

- CFD simulations enable to predict thermal performance of naturally ventilated room which may be applied to improve the designing of the inlet size and location of fresh air valve to set the best results to assess thermal comfort.

- CFD temperatures simulations give overestimated values comparing to in-situ measurements.

- Installation of the fresh air valve at the level of $0.5 \mathrm{~m}$ above the room floor enables mixing fresh air with hot air from radiator, and that is the reason for thermal discomfort sensations.

\section{References}

1. A. Raczkowski, A. Wywiórka, „Assessment of perceived air quality for selected flat in the residential building", in Environmental Engineering III. edited by A. Pawłowski (Taylor \& Francis Group. London. 2010)

2. CEN. EN 15251: Indoor environment input parameters for design and assessment of energy performance of buildings addressing indoor air quality, thermal environment, lighting and acoustics; 2007.

3. J. Janowska, M.K. Widomski, M. Iwanek, A. Musz, "Numerical modeling of water flow through straight globe valve", in Environmental Engineering IV. edited by: A. Pawlowski, M.R. Dudzinska, L. Pawlowski (Taylor \& Francis Group. London. 2013)

4. A. Raczkowski, Z. Suchorab, A. CzechowskaKosacka, AIP Conference Proceedings 1866, 040032-1 (2017)

5. A. Raczkowski, Z. Suchorab, B. Połednik, E. Zarzeka-Raczkowska, A. Życzyńska, AIP Conference Proceedings 1988, 020041 (2018)

6. M. Hajdukiewicz, M. Geron, M.M. Keane, Build Environ. 70. 73-89 (2013)

7. P.V. Nielsen, , Build. Environ. 91 (2015)

8. L. Rong, P.V. Nielsen, B. Bjerg, G. Zhang, Comput Electron Agr. 121 (2016)

9. ISO 7730:2005, Ergonomics of the Thermal Environment - Analytical Determination and Interpretation of Thermal Comfort Using Calculation of the PMV and PPD Indices and Local Thermal Comfort Criteria. Geneva: International Organization for Standardization.

10. J. Gao, Y. Wang, P. Wargocki, Build Environ. 92, 200-208 (2015)

11. M. Hajdukiewicz, M. Geron, M.M. Keane, Build Environ. 59, 290-302 (2013)

12. A. Albatayneha, D. Altermanb, A. Pageb, B. Moghtaderib, Energy Procedia 115, 253-264 (2017)

13. CFD 2016 Help: Mechanical ventilation, help.autodesk.com

14. AEC Best Practises, help.autodesk.com

15. J. Song, X. Meng, Procedia Eng. 121, 1475-1481 (2015) 